\title{
OTIMIZAÇÃO DA HIDRÓLISE DA CASEÍNA PARA ELEVAR O TEOR DE PEQUENOS PEPTÍDEOS: EMPREGO DA PEPSINA
}

\author{
RAQUEL LINHARES CARREIRA ${ }^{1}$ \\ VIVIANE DIAS MEDEIROS SILVA ${ }^{2}$ \\ HARRIMAN ALEY MORAIS ${ }^{1}$ \\ SILVANA DA MOTTA ${ }^{3}$ \\ ROBERTO GONÇALVES JUNQUEIRA ${ }^{3}$ \\ MARIALICE PINTO COELHO SILVESTRE ${ }^{3}$
}

\begin{abstract}
RESUMO - Visando à produção de hidrolisados de caseína para uso como suplemento dietético, estudou-se a otimização das condições hidrolíticas, empregando-se a pepsina para elevar os teores de di e tripeptídeos. Os hidrolisados foram fracionados pela CLAE de exclusão molecular, seguida da quantificação dos peptídeos nas frações croma-
\end{abstract}

TERMOS PARA INDEXAÇÃO: Suplemento dietético, hidrólise enzimática, caseína, peptídeos, pepsina.

\section{OPTIMIZATION OF CASEIN HYDROLYSIS TO INCREASE SMALL PEPTIDE CONTENTS: USE OF PEPSIN}

\begin{abstract}
With the aim of producing casein hydrolysates for dietary use, the optimization of the hydrolysis conditions, using pepsin, for increasing di- and tripeptide contents was studied. The hydrolysates were fractionated by size-exclusion HPLC and the rapid Correct Fraction Area method
\end{abstract}

was used for quantifying the peptides. The results showed that in order to have the best peptide profile for special diets, certain parameters, such as $\mathrm{pH}$, enzyme:substrate ratio and temperature need to be fixed. Also, the production costs must be taken into account.

tográficas pelo método rápido da Área Corrigida da Fração. Pelos resultados obtidos, infere-se que a obtenção do melhor perfil peptídico, para uso em dietas especiais, depende da definição de alguns parâmetros, tais como, $\mathrm{pH}$, relação enzima:susbtrato e temperatura. Além disso, o custo envolvido na preparação deve ser considerado.

INDEX TERMS: Dietary supplement, enzymatic hydrolysis, casein, peptides, pepsin.

\section{INTRODUÇÃO}

O interesse pelos hidrolisados protéicos aumentou nos últimos anos, uma vez que foi mostrado que preparações contendo pequenos peptídeos, especialmente di e tripeptídeos, provenientes da hidrólise parcial de proteínas são absorvidas mais rápida e completamente do que uma mistura equivalente de aminoácidos livres (Hara et al., 1984; Kheohane et al., 1985; Grimble et al., 1986).

A introdução na dieta de hidrolisados ricos em pequenos peptídeos pode ser importante, no sentido de propiciar melhor utilização das proteínas, principal- mente em determinadas situações como a que ocorre em indivíduos com alergias a determinadas proteínas ou com intolerância alimentar, nos casos de deficiência enzimática (Chataud et al., 1988; González-Tello et al., 1994).

Os hidrolisados protéicos têm sido utilizados em países desenvolvidos na fabricação de alimentos especiais para diversos grupos, tais como os recém-nascidos prematuros, as crianças com diarréia, gastroenterite, má-absorção e fenilcetonúria e ainda para pessoas com alergia a determinadas proteínas, visto que o decréscimo no tamanho dos peptídeos tem relação direta com a diminuição da imunogenicidade (Freitas et al., 1993).

1. Mestre em Ciência de Alimentos, Faculdade de Farmácia/UFMG, Av. Olegário Maciel, 2360 - Lourdes 30.180-112 - Belo Horizonte, MG.

2. Bolsista de Aperfeiçoamento da FAPEMIG, Faculdade de Farmácia/UFMG.

3. Professor do Departamento de Alimentos da Faculdade de Farmácia/UFMG. 
O valor nutricional dos hidrolisados depende da proteína de origem, do tipo de hidrólise (enzimática ou química) e do tamanho da cadeia peptídica. A qualidade de uma proteína alimentar é função da natureza e de sua composição em aminoácidos, especialmente os essenciais (Loosen et al., 1991; Anantharaman \& Finot, 1993). A caseína foi selecionada para o presente trabalho devido ao alto valor nutricional e à elevada susceptibilidade à ação catalítica de todas as proteases conhecidas (Adachi et al., 1991). A pepsina atua em uma faixa de $\mathrm{pH}$ de 1 a 4 , na qual a maioria das enzimas ou proteínas sofre desnaturação (Yamamoto, 1975).

Com este trabalho, objetivou-se estudar diferentes condições de hidrólise, empregando-se a pepsina, a fim de se obter hidrolisados de caseína com elevado teor de pequenos peptídeos.

\section{MATERIAL E MÉTODOS}

O sistema de CLAE consistiu de uma bomba isocrática (série HP1100) e um detector espectrofotométrico em UV-VIS acoplado a um computador com software HPchemstation (Avondale, USA). Foi utilizada a coluna cromatográfica [poli(2-hidroxietilaspartamida) sílica - PHEA], $250 \mathrm{X}$ 9,4 mm, $5 \mu \mathrm{m}$ e $200 \AA$ (PolylC, Columbia, MD). A pepsina suína (P6887) e a caseína bovina (C7078) foram adquiridas da Sigma (St.Louis, MO). O ácido clorídrico e o ácido fórmico foram obtidos da Merck (Darmstadt, Germany). A água para uso no cromatógrafo foi purificada através da passagem pelo Sistema de Purificação de Água Aries (Vaponics, EUA).
Todos os solventes usados foram cuidadosamente desgaseificados em banho de ultra-som.

\section{Preparo dos hidrolisados de caseína}

Foram preparados sete hidrolisados protéicos. As soluções de caseína a $0,25 \mathrm{~g} \%$ (p/v) em tampão fosfato $0,01 \mathrm{molL}^{-1}(\mathrm{pH} \mathrm{1,9}$ e 2,5) foram, inicialmente, pré-aquecidas em banho-maria a $90^{\circ} \mathrm{C}$ por $30 \mathrm{~min}$. Posteriormente, a temperatura foi ajustada para cada caso, e a pepsina foi adicionada numa dada concentração, de maneira a obter a relação Enzima:Substrato desejada. $\mathrm{O}$ tempo total de reação foi de 5 horas, com exceção de H5 e H6, para os quais a hidrólise teve duração de 3 horas e 1 hora, respectivamente. Os parâmetros das reações estão apresentados na Tabela 1.

\section{Fracionamento dos hidrolisados de caseína}

O fracionamento dos hidrolisados foi realizado por CLAE-EM em coluna PHEA, como descrito por Silvestre et al. (1994b). As amostras foram dissolvidas a uma concentração de $1 \%$ (p/v) em solução de ácido fórmico $0,05 \mathrm{~mol} \mathrm{~L}^{-1}$ (pH próximo a 2,5) e cromatografadas à temperatura ambiente, sob condições isocráticas, a um fluxo de $0,5 \mathrm{mLmin}^{-1}$, durante $35 \mathrm{~min}$. A fase móvel foi filtrada, através de membrana de $0,45 \mu \mathrm{m}$, e sonicada imediatamente antes do uso. A detecção dos picos cromatográficos foi efetuada em três comprimentos de onda: 230, 280 e $300 \mathrm{~nm}$. As amostras foram analisadas em triplicatas e as frações foram separadas de acordo com o tempo de retenção, sendo F1 de 13,7 a 18,2min; F2 de 18,2 a 21,7 min; F3 de 21,7 a 22,7 min; e F4 de 22,7 a $32 \mathrm{~min}$.

TABELA 1 - Parâmetros hidrolíticos empregados no preparo dos hidrolisados de caseína pela pepsina.

\begin{tabular}{ccccc}
\hline Hidrolisados protéicos & Temperatura $\left({ }^{\mathbf{o}} \mathbf{C}\right)$ & $\mathbf{p H}$ & $* \mathbf{E : S}(\%)$ & Tempo (h) \\
\hline $\mathrm{H} 1$ & $40^{\circ} \mathrm{C}$ & 1,9 & 2 & 5 \\
$\mathrm{H} 2$ & $40^{\circ} \mathrm{C}$ & 1,9 & 4 & 5 \\
$\mathrm{H} 3$ & $40^{\circ} \mathrm{C}$ & 2,5 & 4 & 5 \\
$\mathrm{H} 4$ & $37^{\circ} \mathrm{C}$ & 1,9 & 4 & 3 \\
$\mathrm{H} 5$ & $40^{\circ} \mathrm{C}$ & 1,9 & 4 & 1 \\
$\mathrm{H} 6$ & $40^{\circ} \mathrm{C}$ & 1,9 & 4 & 5 \\
$\mathrm{H} 7$ & $60^{\circ} \mathrm{C}$ & 1,9 & 4 \\
\hline
\end{tabular}

\footnotetext{
* E:S = relação enzima:substrato
}

Ciênc. agrotec., Lavras. V.27, n.3, p.625-634, maio/jun., 2003 
Quantificação de peptídeos e aminoácidos livres nos hidrolisados de caseína

O método rápido da Área Corrigida da Fração (ACF) desenvolvido por Silvestre et al. (1994b), foi utilizado para quantificar os peptídeos e aminoácidos livres presentes nos hidrolisados de caseína. As amostras foram fracionadas e os valores da ACF, calculados, a partir de uma curva padrão, preparada como descrito por Morato et al. (2000).

\section{Análise Estatística}

Todas as determinações foram realizadas em triplicata. Para a determinação das diferenças entre as médias e do conteúdo de aminoácidos das frações cromatográficas dos hidrolisados de caseína, foram feitos a Análise Fatorial e o Teste de Duncan (Pimentel-Gomes, 1990).

\section{RESULTADOS E DISCUSSÃO}

Fracionamento por cromatografia líquida de alta eficiência - exclusão molecular

Como exemplo, o perfil cromatográfico do hidrolisado H4, a $230 \mathrm{~nm}$, está apresentado na Figura 1. Conforme descrito anteriormente (Silvestre et al., 1994a; Morato et al., 2000), os hidrolisados protéicos foram separados em quatro frações. A fração 1 corresponde aos peptídeos que contêm mais que 7 resíduos de aminoácidos; a fração 2, de 4 a 7 resíduos; a fração 3, de di e tripeptídeos e a fração 4 , que contêm os aminoácidos livres. Os últimos dois picos na fração 4 correspondem à tirosina (pico Y) e triptofano (pico W). Assim sendo, a técnica de CLAE-EM empregada no presente trabalho mostrou ser eficiente na caracterização de hidrolisados protéicos, especialmente nos casos em que o interesse está voltado para o fracionamento de peptídeos de baixa massa molecular, ou seja, inferior a 1000 Da.

Muitos trabalhos são relatados na literatura abordando o fracionamento de peptídeos de hidrolisados protéicos, de acordo com o tamanho molecular, empregando diferentes técnicas. A maioria refere-se aos peptídeos de elevada massa molecular (> $1000 \mathrm{Da})$. O principal método refere-se à eletroforese em gel de poliacrilamida - dodecil sulfato de sódio, SDS-PAGE (Schmidt \& Poll, 1991; Perea et al., 1993; Gallagher et al., 1994); cromatografia de exclusão molecular, SEC (Vallejo-Cordoba et al., 1986; Deeslie \& Cheryan, 1988; Adachi et al., 1991; Zhang et al., 1992; Parrado et al., 1993); CLAE de troca de ligante, CLAE-TL (Ford et al., 1986; Armstead \& Ling, 1991; Aubry et al., 1992); e CLAE-EM (Chobert et al., 1988; Lemieux \& Amiot, 1989; Visser et al., 1992). Entretanto, o emprego dessas técnicas tem demonstrado uma série de inconvenientes, tais como interações secundárias (eletrostáticas ou hidrofóbicas) entre os solutos e a fase estacionária (Kopaciewicz \& Regnier, 1982; Golovchenko et al., 1992) e a ineficiência para separar pequenos

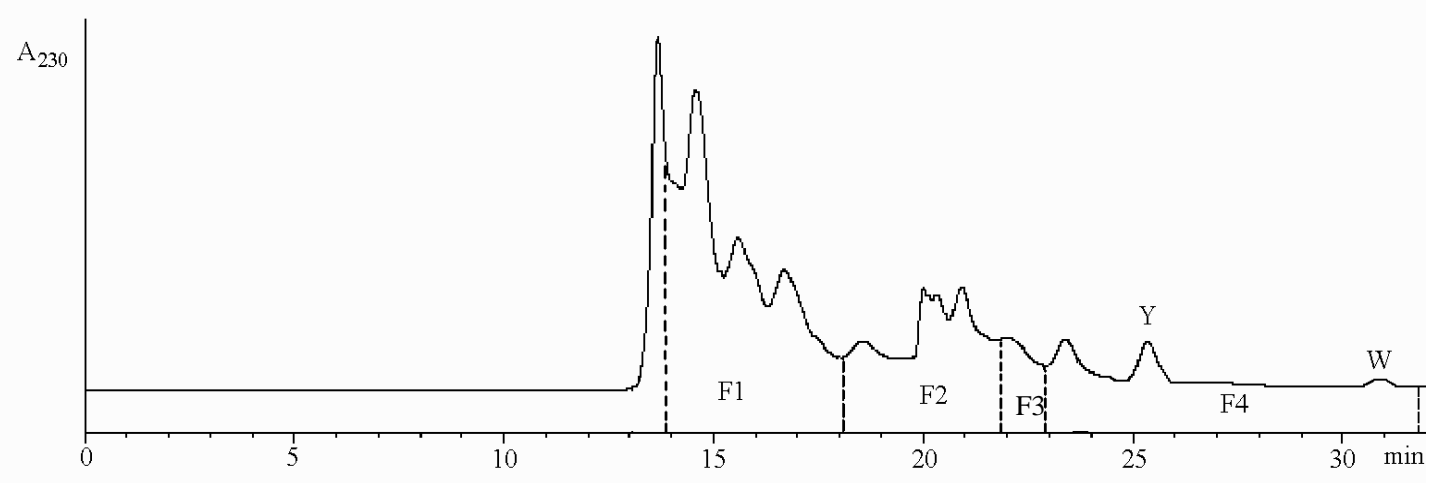

FIGURA 1 - Perfil cromatográfico do hidrolisado $\mathrm{H} 4\left(4 \%, \mathrm{pH} 1,9,37^{\circ} \mathrm{C}, 5 \mathrm{~h}\right)$ a $230 \mathrm{~nm}$. F1: grandes peptídeos (> 7 resíduos de aminoácidos); F2: médios peptídeos (4 a 7 resíduos de aminoáciods); F3: di-e tripeptídeos; F4: aminoácidos livres. $\mathrm{Y}=$ pico da tirosina, $\mathrm{W}=$ pico do triptofano. 
peptídeos (Lemieux et al., 1991). O uso da SEC e da CLAE-TL mostrou ser capaz de separar apenas peptídeos de aminoácidos. Outros autores, empregando a CLAE-EM (Lemieux \& Amiot, 1989, Lemieux et al., 1991) ou a CLAE capilar (Davis \& Lee, 1992), relataram a dificuldade de separar os peptídeos de acordo com o tamanho da cadeia, tendo observado uma superposição de pesos moleculares.

Distribuição de tirosina e triptofano nas frações cromatográficas

Para uma avaliação mais precisa dos hidrolisados protéicos, calculou-se a distribuição de tirosina e triptofano nas diferentes frações cromatográficas, especialmente na fração F3, visto que di e tripeptídeos re- presentam a forma mais facilmente assimilável desses dois aminoácidos. Além disso, considerando-se a baixa solubilidade da tirosina livre, seria interessante a sua substituição em preparações dietéticas, por di e tripeptídeos contendo altos teores de tirosina solúvel (Furst et al., 1990). Quanto ao triptofano, acrescenta-se, ainda, que sendo esse aminoácido importante para reduzir a latência do sono em crianças, seria importante a sua avaliação, especialmente no caso do preparo de formulações infantis, à base de hidrolisados protéicos (Steinberg et al., 1992).

A distribuição foi estimada baseando-se nas áreas relativas dos dois resíduos a $230 \mathrm{~nm}$. Como apresentado na Tabela 2 , o hidrolisado $\mathrm{H} 7$ foi o que apresentou os teores mais elevados de tirosina e triptofano na forma de di e tripeptídeos.

TABELA 2 - Distribuição de tirosina e triptofano nas frações cromatográficas dos hidrolisados de caseína, a $230 \mathrm{~nm}$.

\begin{tabular}{cccccc}
\hline \multirow{2}{*}{ Hidrolisados } & Aminoácidos & \multicolumn{5}{c}{ Frações cromatográficas (\% da área total) } \\
\cline { 3 - 6 } & & F1 & F2 & F3 & F4 \\
\hline \multirow{2}{*}{ H1 } & Tyr & 0,70 & 8,48 & 82,00 & 8,81 \\
& Hrp & 11,07 & 6,62 & 62,8 & 19,51 \\
& Tyr & 45,64 & 16,24 & 24,11 & 14,02 \\
& Hrp & 6,65 & 16,06 & 23,24 & 54,05 \\
& Tyr & 1,96 & 21,52 & 40,30 & 36,20 \\
H4 & Trp & 13,29 & 8,07 & 52,56 & 26,08 \\
& Tyr & 11,27 & 20,70 & 47,26 & 20,77 \\
H5 & Trp & 11,69 & 20,14 & 44,22 & 23,95 \\
& Tyr & 10,15 & 68,17 & 15,48 & 6,20 \\
H6 & Trp & 14,66 & 6,35 & 41,17 & 37,82 \\
& Tyr & 8,79 & 45,73 & 37,38 & 8,10 \\
& Trp & 20,65 & 6,17 & 16,29 & 56,89 \\
& Tyr & 0,04 & 0,42 & 98,48 & 1,06 \\
& Trp & 0,21 & 0,05 & 99,37 & 0,37 \\
\hline
\end{tabular}

*Os valores representam a média das triplicatas. F1: grandes peptídeos (> 7 resíduos de aminoácidos); F2: médios peptídeos (4 a 7 resíduos de aminoácidos); F3: di-e tripeptídeos; F4: aminoácidos livres.

Ciênc. agrotec., Lavras. V.27, n.3, p.625-634, maio/jun., 2003 


\section{Comparação entre os diferentes tratamentos enzimáticos}

\section{Efeito da relação Enzima:Substrato $(\mathrm{E}: \mathrm{S})$}

A influência da relação enzima : substrato na ação da pepsina sobre a caseína pode ser avaliada na Figura 2. Observa-se que a duplicação da relação enzima : substrato de $2 \%$ para $4 \%$ (hidrolisados $\mathrm{H} 1$ e $\mathrm{H} 2$, respectivamente), apesar de não ter alterado significativamente o conteúdo das frações F1, F2 e F4, contribuiu para elevar os níveis de di e tripeptídeos de $2 \%$ para $10 \%$, apresentando-se como uma alternativa vantajosa na obtenção de hidrolisados protéicos ricos em pequenos peptídeos. A relação enzima : substrato, assim como o tempo de hidrólise, poderiam ser aumentados, a fim de se obter graus de hidrólise mais acentuados. Essas alterações, entretanto, devem ser avaliadas economicamente, no caso de uma aplicação industrial. Sabe-se, ainda, que reação hidrolítica com duração superior a 5 horas pode favorecer a contaminação microbiana dessas preparações protéicas (Chataud et al., 1988; Loosen et al., 1991).
Considerando-se os principais pontos de afinidade da pepsina sobre a molécula de caseína, esse aumento no teor de di e tripeptídeos, devido à maior quantidade de enzima adicionada, era esperado (Ottesen \& Svendsen, 1970; Smith et al., 1970; Markland \& Smith, 1971). Ao elevar a relação E:S da subtilisina (enzima do Bacillus licheniformis) na mesma proporção, no preparo de hidrolisados de caseína, Morato et al. (2000) mostraram uma alteração significativa de todas as frações, tendo sido observado um decréscimo dos teores de grandes peptídeos e de aminoácidos livres, e um aumento dos níveis de médios e di e tripeptídeos. Esses resultados diferem da afirmativa de González-Tello et al. (1994) de que uma alteração na relação E:S não exerce qualquer influência na distribuição de peptídeos nas frações cromatográficas de hidrolisados protéicos.

Loosen et al. (1991) testaram o emprego da subtilisina na hidrólise da caseína, variando-se a relação E:S de 1 a $4 \%$, sendo os melhores resultados obtidos empregando-se a relação E:S de $2 \%$, levando à obtenção de um hidrolisado contendo $75 \%$ de di e tripeptídeos e apenas $5 \%$ de aminoácidos livres.

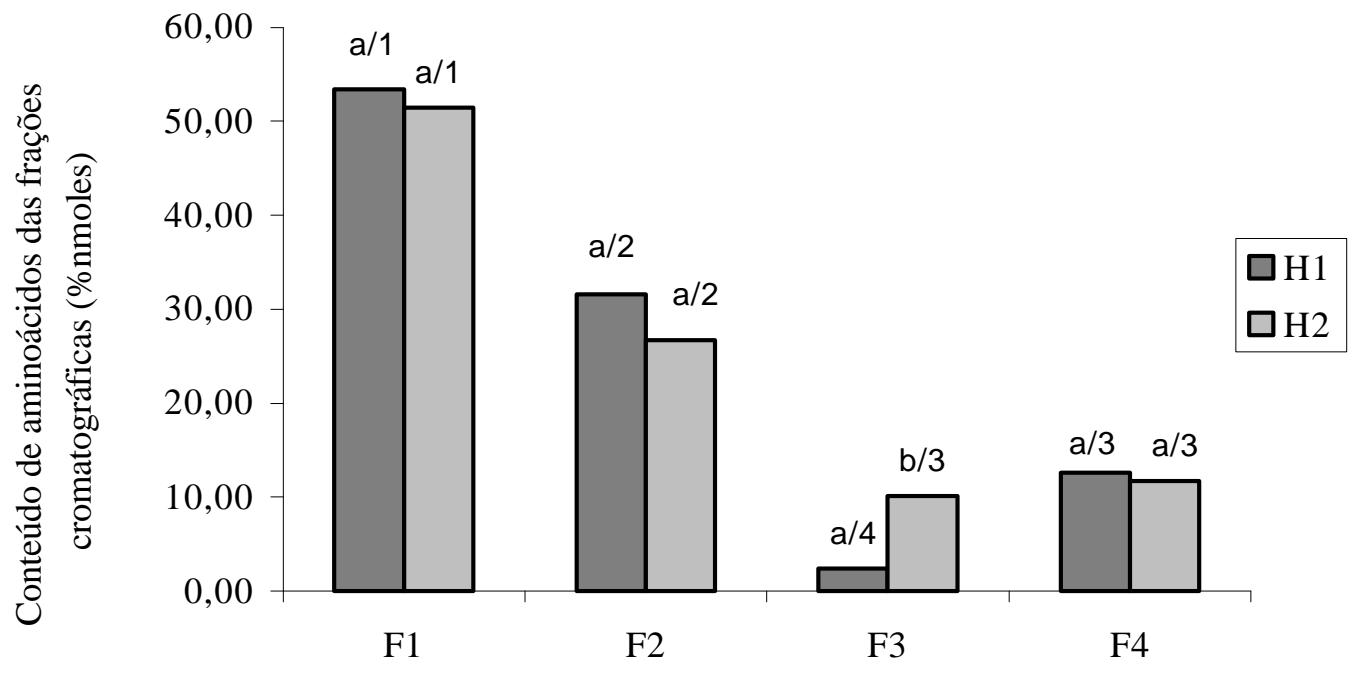

Frações cromatográficas

FIGURA 2 - Efeito da relação E:S na ação da pepsina sobre a caseína. H1: 2\%; H2 : 4\%. F1: grandes peptídeos (> 7 resíduos de aminoácidos); F2: médios peptídeos (4 a 7 resíduos de aminoácidos); F3: di- e tripeptídeos; F4: aminoácidos livres. Os resultados representam a média das triplicatas. Médias indicadas por letras iguais não diferem entre si $(\mathrm{p}<0,05)$ na comparação de uma mesma fração para diferentes hidrolisados. Médias indicadas por números iguais não diferem entre si $(\mathrm{p}<0,05)$ na comparação de diferentes frações de um hidrolisado.

Ciênc. agrotec., Lavras. V.27, n.3, p.625-634, maio/jun., 2003 
Por outro lado, Freitas et al. (1993) não observaram uma alteração do perfil cromatográfico de um hidrolisado de caseína, ao aumentar de 3,7 vezes a concentração de pancreatina. Segundo os autores, esse limite aparente na hidrólise da caseína pode estar relacionado, pelo menos em parte, à sua sequiência de aminoácidos e à especificidade da enzima empregada. Apesar de esses resultados estarem de acordo com o relato de González-Tello et al. (1994), uma explicação para isso poderia ser a de que os suportes cromatográficos empregados por esses autores teriam sido menos eficientes para a separação de peptídeos, de acordo com o tamanho da cadeia, especialmente de di e tripeptídeos (Kopaciewicz \& Regnier, 1982; Lemieux et al., 1991).

Com relação à distribuição de tirosina e triptofano (Tabela 2), o aumento na relação E:S de $2 \%$ para 4\% (hidrolisados $\mathrm{H} 1$ e $\mathrm{H} 2$, respectivamente) foi desvantajoso, pois levou à redução no conteúdo de ambos os aminoácidos na forma de di e tripeptídeos. Por outro lado, ao promover essa mesma alteração empregandose a subtilisina para hidrolisar a caseína, Morato et al.
(2000) obtiveram resultados benéficos, apresentando teores mais elevados desses aminoácidos na fração F3.

\subsection{Efeito da temperatura}

O efeito da temperatura na ação da pepsina sobre a caseína está apresentado na Figura 3. Observa-se que a variação da temperatura de $37^{\circ} \mathrm{C}$ para $40^{\circ} \mathrm{C}$ (hidrolisado $\mathrm{H} 4$ e $\mathrm{H} 2$, respectivamente) não alterou os teores de médios e di e tripeptídeos, como também os de aminoácidos livres, mas, por outro lado, contribuiu para reduzir o teor de grandes peptídeos (62\% para $51 \%)$.

Aumentando-se ainda mais a temperatura de $40^{\circ} \mathrm{C}$ para $60^{\circ} \mathrm{C}(\mathrm{H} 2$ e $\mathrm{H} 7$, respectivamente), obteve-se uma elevação na quantidade de grandes peptídeos de $51 \%$ (H2) para $57 \%$ (H7), e o conteúdo de di e tripeptídeos foi reduzido de $10 \%$ em $\mathrm{H} 2$ para $5 \%$ em H7. Não houve diferenças em relação aos níveis de médios peptídeos e aminoácidos livres. Conclui-se, portanto, que o emprego de temperatura superior a $37^{\circ} \mathrm{C}$ apresentou vantagem mínima, do ponto de vista nutricional, pois somente provocou redução dos teores de grandes peptídeos, ao passar para $40^{\circ} \mathrm{C}$.

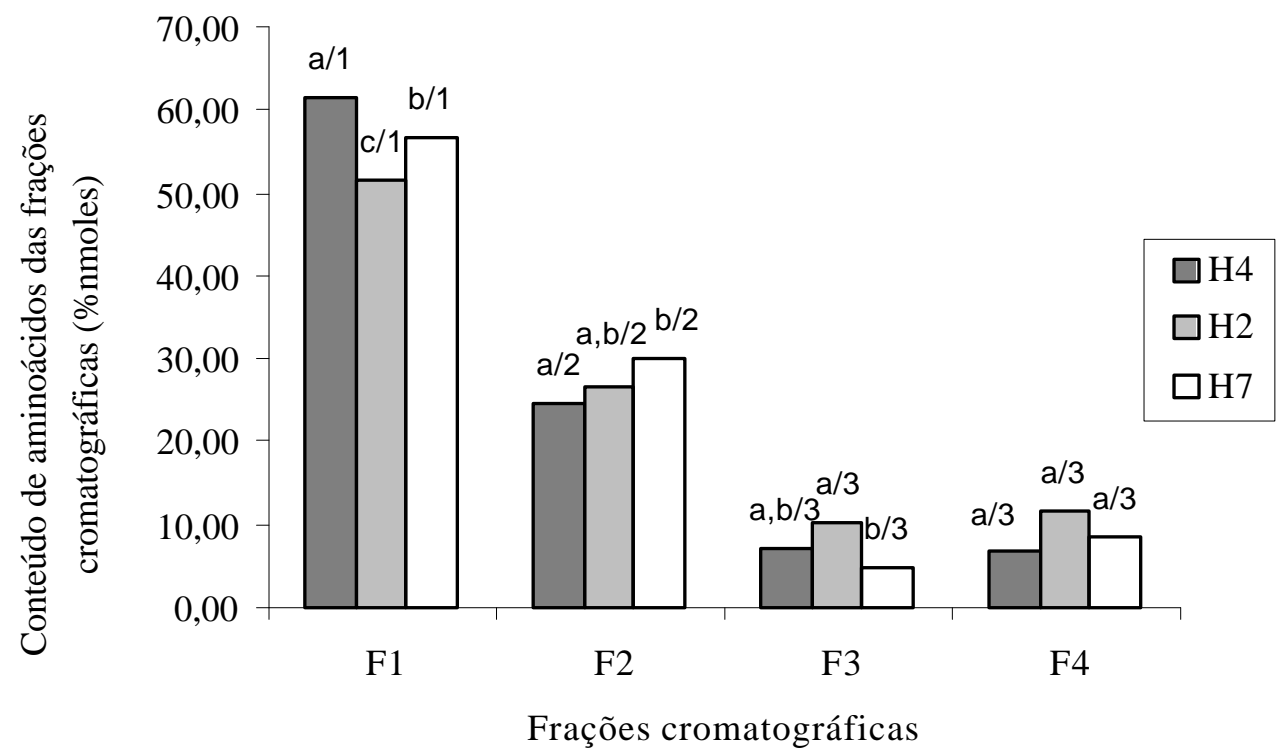

FIGURA 3 - Efeito da temperatura na ação da pepsina sobre a caseína. $\mathrm{H} 2$ : $40^{\circ}$; $\mathrm{H} 4: 37^{\circ} \mathrm{C}$; H7: $60^{\circ} \mathrm{C}$. \% . F1: grandes peptídeos (> 7 resíduos de aminoácidos); F2: médios peptídeos (4 a 7 resíduos de aminoácidos); F3: di- e tripeptídeos; F4: aminoácidos livre. Os resultados representam a média das triplicatas. Médias indicadas por letras iguais não diferem entre si $(p<0,05)$ na comparação de uma mesma fração para diferentes hidrolisados. Médias indicadas por números iguais não diferem entre si $(p<0,05)$ na comparação de diferentes frações de um hidrolisado.

Ciênc. agrotec., Lavras. V.27, n.3, p.625-634, maio/jun., 2003 
Assim, a temperatura de $37^{\circ} \mathrm{C}$ foi a escolhida para o preparo dos hidrolisados, uma vez que o emprego de valores mais elevados poderia ocasionar uma elevação no custo final do produto. O efeito da elevação da temperatura (de 40 para $50^{\circ} \mathrm{C}$ ) sobre o perfil peptídico de hidrolisados de caseína, obtidos pela ação da subtilisina, foi, também, estudado recentemente. Assim, Morato et al. (2000) mostraram que o emprego da temperatura acima de $40^{\circ} \mathrm{C}$ foi prejudicial do ponto de vista nutricional, tendo obtido resultados semelhantes ao presente trabalho, ao se passar de 40 para $60^{\circ} \mathrm{C}$.

Esses resultados não estão de acordo com Chataud et al. (1988) e Loosen et al. (1989), que sugerem o emprego de temperaturas acima de $40^{\circ} \mathrm{C}$ no preparo de hidrolisados subtilisínicos ricos em di e tripeptídeos. Segundo esses autores, esse procedimento pode, ainda, contribuir para a redução do tempo de hidrólise, sem provocar significativa desnaturação da enzima, além de minimizar a contaminação microbiana.

A distribuição de tirosina e triptofano (Tabela 2) também foi influenciada pela mudança na temperatura de hidrólise. Assim, ao passar de $37^{\circ} \mathrm{C}(\mathrm{H} 4)$ para $40^{\circ} \mathrm{C}$ (H2), observou-se uma redução nos teores desses aminoácidos na fração F3. Efeito contrário foi obtido ao se elevar ainda mais a temperatura de $40^{\circ} \mathrm{C}(\mathrm{H} 2)$ para $60^{\circ} \mathrm{C}(\mathrm{H} 7)$, e esse último caso representa o mais vanta- joso tratamento, dentre os três estudados. Por outro lado, Morato et al. (2000) observaram um aumento de 5 vezes apenas no conteúdo de tirosina presente na forma de di e tripeptídeos, ao elevar a temperatura de $40^{\circ} \mathrm{C}$ para $50^{\circ} \mathrm{C}$, utilizando-se a subtilisina na hidrólise da caseína.

\subsection{Efeito do pH}

A influência do pH na ação da pepsina sobre a caseína está representada na Figura 4. O melhor resul-

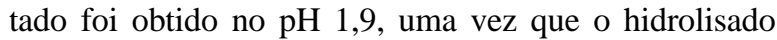
$\mathrm{H} 2$ apresentou o menor teor de grandes peptídeos $(51 \%)$ e maior de di e tripeptídeos (10\%), quando comparado ao hidrolisado preparado no $\mathrm{pH}$ 2,5 (H3). Em relação às quantidades de médios peptídeos e aminoácidos livres, não houve diferenças significativas entre esses dois hidrolisados.

Considerando-se que a faixa ótima de $\mathrm{pH}$ para a ação da pepsina é de 1 a 4, pode-se concluir que os resultados aqui descritos assemelham-se aos apresentados por Morato et al. (2000), uma vez que, ao trabalhar com dois valores de $\mathrm{pH}(7,5$ e 8,0$)$ situados na faixa ótima de ação da subtilisina $(7,0-8,0)$, foram obtidos diferentes perfis cromatográficos. Ao contrário do que foi descrito para as frações cromatográficas, a melhor

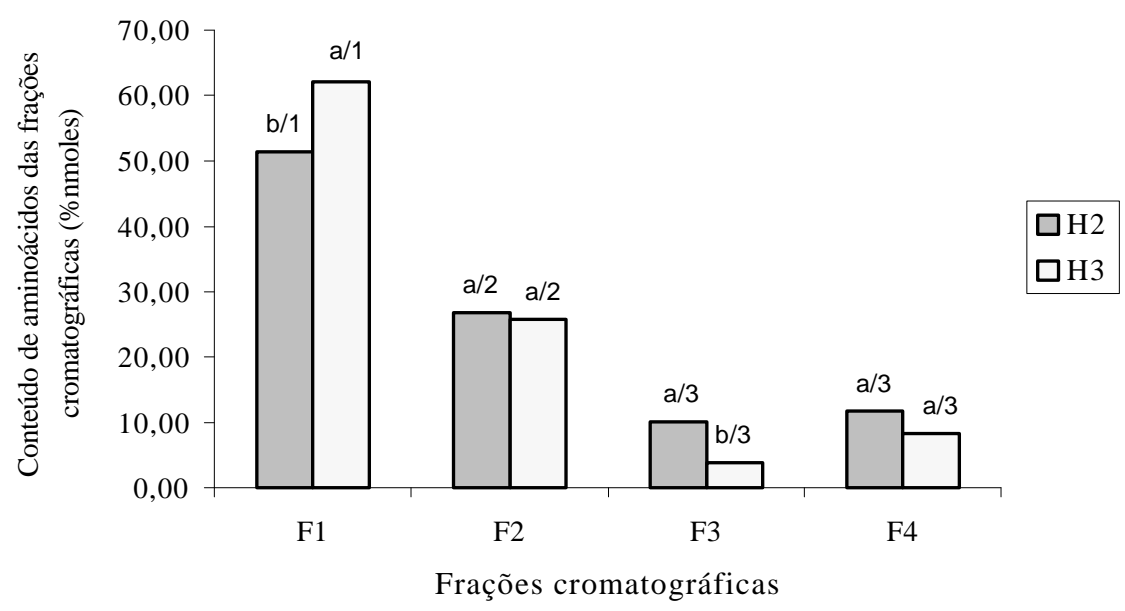

FIGURA 4 - Efeito do pH na ação da pepsina sobre a caseína. H2: pH = 1,9; H3: pH = 2,5. \%. F1: Grandes peptídeos (> 7 resíduos de aminoácidos); F2: médios peptídeos (4 a 7 resíduos de aminoácidos); F3: di e tripeptídeos; F4: aminoácidos livres. Os resultados representam a média das triplicatas. Médias indicadas por letras iguais não diferem entre si $(\mathrm{p}<0,05)$ na comparação de uma mesma fração para diferentes hidrolisados. Médias indicadas por números iguais não diferem entre si $(\mathrm{p}<0,05)$ na comparação de diferentes frações de um hidrolisado. 
distribuição dos aminoácidos aromáticos (Tabela 2) foi obtida no pH 2,5, visto que o hidrolisado $\mathrm{H} 3$ apresentou os teores mais elevados desses aminoácidos na forma de di e tripeptídeos.

Ainda é importante ressaltar que esse comportamento pode ser explicado provavelmente pela carga dos resíduos de aminoácidos nas moléculas da enzima e da caseína em diferentes valores de $\mathrm{pH}$, afetando a disponibilidade das ligações peptídicas ao ataque enzimático e, conseqüentemente, alterando os produtos obtidos.

\section{CONCLUSÃO}

A ação da pepsina foi mais eficiente na produção de di e tripeptídeos, quando se empregou E:S a 4\%, $\mathrm{pH}$ de 1,9 e temperatura de $37^{\circ} \mathrm{C}(\mathrm{H} 4)$ ou $40^{\circ} \mathrm{C}(\mathrm{H} 2)$. Além disso, esses hidrolisados (H4 e H2) apresentaram outras vantagens, para serem usados em dietas especiais, ou seja, maiores teores de peptídeos com massa molecular média de 500Da (F2 + F3), a menor porcentagem de peptídeos com massa molecular maior que 800Da (F1), bem como o nível mais baixo de aminoácidos livres. Em relação à distribuição de tirosina e triptofano na forma de di e tripeptídeos, o emprego da temperatura de $60^{\circ} \mathrm{C}(\mathrm{H} 7)$ apresentou teores mais elevados desses dois aminoácidos na fração F3; entretanto, para a escolha da melhor preparação enzimática, deve também ser considerada a vantagem, do ponto de vista econômico, de se aplicar temperaturas mais baixas.

\section{AGRADECIMENTOS}

À Fapemig e ao CNPq, pelo apoio financeiro.

\section{REFERÊNCIAS BIBLIOGRÁFICAS}

ADACHI, S.; KIMURA, Y.; MURAKAMI, K.; MATSUNO, R.; YOKOGOSHI, H. Separation of peptide groups with definite characteristics from enzymatic protein hydrolysate. Agricultural and Biological Chemistry, Tokyo, v. 55, n. 4, p. 925-932, 1991.

ANANTHARAMAN, K.; FINOT, P. A. Nutritional aspects of food proteins in relation to technology. Food Review International, New York, v. 9, p. 629-655, 1993.

ARMSTEAD, I. P.; LING, J. R. Chromatographic separation of mixed peptides from amino acids in biological digests with volatile buffers. Journal of Chromatography, Amsterdam, v. 586, n. 3, p. 259-263, 1991.
AUBRY, A. F.; CAUDE, M.; ROSSET, R. Separation and identification of dipeptides in an hydrolyzed brain extract. Chromatography, Denver, v. 33, n. 3, p. 533538, 1992.

CHATAUD, J.; DESREUMEUX, S.; CARTWRIGHT, T. Procédé de fabrication d'un hydrolysat enzymatique de protéines riche en di- et tri-peptides, utilisable notamment en nutrition artificielle et en dietétique. Neuilly-sur-Seine: Laboratório Roger Bellon, 1988.

CHOBERT, J. M.; SITOHY, M. Z.; WHITAKER, J. R. Solubility and emulsifying properties of caseins modified enzymatically by Staphylococcus aureus V8 protease. Journal of Agricultural and Food Chemistry, Washington, v. 36, n. 5, p. 220-224, 1988.

DEESLIE, W. D.; CHERYAN, M. Functional properties of soy protein hydrolysates from a continuous ultrafiltration reactor. Journal of Agricultural and Food Chemistry, Washington, v. 36, n. 11, p. 26-31, 1988.

DAVIS, M.; LEE, T. D. Analysis of peptide mixtures by capillary high performance liquid chromatography: a practical guide to small-scale separations. Protein Science, New York, v. 1, p. 935-944, 1992.

FORD, C.; GRIMBLE, G. K.; HALLIDAY, D.; SILK, D. B. A. Gas chromatography-mass spectrometry analysis of dipeptides in nutritionally significant partial enzymic hydrolysates of ovalbumin and casein. Biochemical Society Transactions, Essex, v. 14, p. 12911293, 1986.

FREITAS, O.; PADOVAN, G. J.; VILELA, L.; SANTOS, J. E.; OLIVEIRA, J. E. D. de; GREENE, L. J. Characterization of protein hydrolysates prepared for enteral nutrition. Journal of Agricultural and Food Chemistry, Washington, v. 41, n. 8, p. 1432-1438, 1993.

FURST, P.; ALBERS, S.; STEHLE, P. Dipeptides in clinical nutrition. Proceedings of the Nutrition Society, New Yok, v. 49, n. 3, p. 343-359, 1990.

GALLAGHER, J.; KANEKANIAN, A. D.; EVANS, E. P. Hydrolysis of casein: a comparative study of two proteases and their peptide maps. International Journal of Food Science Technology, London, v. 29, n. 3, p. 79-285, 1994.

Ciênc. agrotec., Lavras. V.27, n.3, p.625-634, maio/jun., 2003 
GOLOVCHENKO, N.; KATAEVA, I. A.; AKIMENKO, $\mathrm{V}$. K. Analysis of $\mathrm{pH}$-dependent protein interactions with gel filtration medium. Journal of Chromatography, Amsterdam, v. 591, n. 4, p. 121-128, 1992.

GONZÁLEZ-TELLO, P.; CAMACHO, F.; JURADO, E.; PAÉZ, M. P.; GUADIX, E. M. Enzymatic hydrolysis of whey proteins. II. Molecular-weight range. Biotechnology and Bioengineering, New York, v. 44, n. 4, p. 529-32, 1994.

GRIMBLE, G. K.; KEOHANE, P. P.; HIGGINS, B. E.; KAMINSKI JÚNIOR, M. V.; SILK, D. B. A. Effect of peptide chain length on amino acid and nitrogen absorption from two lactoalbumin hydrolysates in the normal human jejunum. Clinical Science, Essex, v. 71, n. 1 , p. $65-69,1986$.

HARA, H.; FUNABIKI, R.; IWATA, M.; YAMAZAKI, K. Portal absorption of small peptides in rats under unrestrained conditions. Journal of Nutrition, Bethesda, v. 114, n. 3, p. 1122-1129, 1984.

KEOHANE, P. P.; GRIMBLE, G. K.; BROWN, B.; SPILLER, R. C. Influence of protein composition and hydrolysis method on intestinal absorption of protein in man. Gut, London, v. 26, n. 4, p. 907-913, 1985.

KOPACIEWICZ, W.; REGNIER, F. E. Nonideal sizeexclusion chromatography of proteins: effects of $\mathrm{pH}$ at low ionic strength. Analytical Biochemistry, San Diego, v. 126, n. 13, p. 8-16, 1982.

LEMIEUX, L.; AMIOT, J. Application of reversed-phase high-performance liquid chromatography to separation of peptides from phosphorylated and dephosphorylated casein hydrolysates. Journal of Chomatography, Amsterdam, v. 73, n. 1, p. 189-206, 1989.

LEMIEUX, L.; PIOT, J. M.; GUILLOCHON, D.; AMIOT, J. Study of the efficiency of a mobile phase used in size-exclusion HPLC for the separation of peptides from a casein hydrolysate according to their hydrodynamic volume. Journal of Chomatography A, Amsterdam, v. 32, n. 3, p. 499-504, 1991.

LOOSEN, P. C.; BRESSPOLLIER, P. R.; JULIEEN, A. R.; PEJOAN, C. H.; VERNEUIL, B. Procede pour preparer um hydrolysat enzymatique: Tessenderlo Cheemie n. v. [BE/BE]; Stationsstraat, B-3980 Tessenderlo (BE). A23J3/34, C12P21/06 C12S3/14, C07K15/00//A61K37/18, A23J3/04, 3/14. FR-
PCT/BE91/00001, W091/10369. 11 de janeiro de 1991. [S.1.: s.n.], 1991.

MARKLAND, F. S.; SMITH, E. L. Subtilisins: primary structure, chemical and physical properties. In: BOYER, P. D. The enzymes. 3. ed. New York: Academic, 1971. v. 3, p. 561-607.

MORATO, A. F.; CARREIRA, R. L.; JUNQUEIRA, R. G.; SILVESTRE, M. P. C. Optimization of casein hydrolysis for obtaining high contentes of small peptides: use of subtilisin and trypsin. Journal of Food Composition and Analysis, Rome, v. 13, n. 3, p. 101-117, 2000.

OTTESEN, M.; SVENDSEN, I. The subtilisins. In: PERLMANN, G. E.; LORAND, L. Proteolytic enzymes: methods in enzymology. New York: Academic, 1970. p. 199-215.

PARRADO, J.; MILLAN, F.; HERNANDEZ-PINZÓN, I.; BAUTISTA, J.; MACHADO, A. Characterization of enzymatic sunflower protein hydrolysates. Journal of Agricultural and Food Chemistry, Washington, v. 41, n. 1, p. 1821-1825, 1993.

PEREA, A.; UGALDE, U.; RODRIGUEZ, I.; SERRA, J. L. Preparation and characterization of whey protein hydrolysates: applications in industrial whey bioconversion processes. Enzyme Microbial Technology, Stoneham, v. 15, n. 11, p. 418-423, 1993.

PIMENTEL-GOMES, F. Curso de estatística experimental. 13. ed. Piracicaba: Nobel, 1990. 467 p.

SCHMIDT, D. G.; POLL, J. K. Enzymatic hydrolysis of whey proteins. Hydrolysis of $\alpha$-lactoalbumin and $\beta$ lactoglobulin in buffer solutions by proteolytic enzymes. Netherlands Milk Dairy Journal, Amsterdam, v. 45 , n. 4 , p. 225-240, 1991.

SILVESTRE, M. P. C.; HAMON, M.; YVON, M. Analyses of protein hydrolysates. 1. Use of poly (2-hydroxyethylaspartamide)-silica column in size-exclusion chromatography for the fracionation of casein hydrolysates. Journal of Agricultural and Food Chemistry, Washington, v. 42, n. 12, p. $72778-2782,1994 a$.

SILVESTRE, M. P. C.; HAMON, M.; YVON, M. Analyses of protein hydrolysates. 2. Characterization of casein hydrolysates by a rapid peptide quantification method. Journal of Agricultural and Food Chemistry, Washington, v. 42, n. 12, p. 2783-2789, 1994b. 
SMITH, E. L.; MARKLAND, F. S.; GLAZER, A. N. Some structure function relatioships in the subtilisins. In: DESNUELLE, P.; NEURATH, D. H.; OTTESEN, M. Structure-function relationshioship of proteolytic enzymes. New York: Academic, 1970. p. 162-172.

STEINBERG, L. A.; O`CONNELL, N. C.; HATCH, T. F.; PICCIANO, M. F.; BIRCH, L. L. Tryptophan intake influences infants` sleep latency. Human Nutrition. Clinical Nutrition, London, v. 122, n. 9, p. 1781-1791, 1992.

VALLEJO-CORDOBA, B.; NAKAI, S.; POWRIE, W. D.; BEVERIDGE, T. Protein hydrolysates for reducing water activity in meat products. Journal of Food Science, Chicago, v. 51, n. 10, p. 1156-1161, 1986.
VISSER, S.; SLAGEN, C. J.; ROBBEN, A. J. P. M. Determination of molecular mass distributions of whey protein hydrolysates by high-performance sizeexclusion chromatography. Journal of Chromatographty, Amsterdam, v. 599, n. 2, p. 205-209, 1992.

YAMAMOTO, A. Proteolytic enzymes. In: REED, G. Enzymes in food processing. 2. ed. London: Academic, 1975. p. 123-179.

ZHANG, Y.; DORJPALAM, B.; HO, C. T. Contribution of peptides to volatile formation in the Maillard reaction of casein hydrolysate with glucose. Journal of Agricultural and Food Chemistry, Washington, v. 40, n. 5, p. 2467-2471, 1992. 